DEMOGRAPHIC RESEARCH

VOLUME 32, ARTICLE 3, PAGES 75-106
PUBLISHED 8 JANUARY 2015

http://www.demographic-research.org/Volumes/Vol32/3/

DOI: 10.4054/DemRes.2015.32.3

Research Article

\title{
A multistate model to project elderly disability in case of limited data
}

Nicole van der Gaag

Govert Bijwaard

\section{Joop de Beer}

\section{Luc Bonneux}

This publication is part of the Special Collection on "Multistate Event History Analysis," organized by Guest Editors Frans Willekens and Hein Putter.

(C) 2015 Nicole van der Gaag et al.

This open-access work is published under the terms of the Creative Commons Attribution NonCommercial License 2.0 Germany, which permits use, reproduction \& distribution in any medium for non-commercial purposes, provided the original author(s) and source are given credit.

See http://creativecommons.org/licenses/by-nc/2.0/de/ 


\section{Table of Contents}

$\begin{array}{lll}1 & \text { Introduction } & 76\end{array}$

2 Method 78

2.1 Estimation of transition rates in an irreversible illness-death model $\quad 79$

$2.2 \quad$ Adding the risk factor obesity 83

$3 \quad$ Two illustrations of disability incidence based scenarios 85

3.1 Estimates of disability incidence based on disability prevalence in 86 the Netherlands
Expansion or compression of disability

$\begin{array}{lll}3.2 & \text { Expansion or compression of disability } & 89 \\ 3.3 & \text { Life expectancy at age } 65 & 90\end{array}$

3.4 Trends in disability 91

3.5 The impact of obesity 92

4 Discussion $\quad 98$

5 Acknowledgements 100

$\begin{array}{ll}\text { References } & 101\end{array}$ 


\title{
A multistate model to project elderly disability in case of limited data
}

\author{
Nicole van der Gaag ${ }^{1}$ \\ Govert Bijwaard $^{2}$ \\ Joop de Beer ${ }^{2}$ \\ Luc Bonneux ${ }^{3}$
}

\begin{abstract}
BACKGROUND

Prevalence of disability depends on when a person becomes disabled (disability incidence) and when he or she dies (mortality). Multistate projection models can take into account both underlying processes of disability prevalence. The application of these models, however, is often hampered by high data requirements.
\end{abstract}

\section{OBJECTIVE}

This paper describes a generic estimation procedure for calculating disability incidence rates and mortality rates by disability status from data on disability prevalence and overall mortality. The procedure allows for the addition of risk factors.

\section{METHODS}

We estimate disability incidence rates from disability prevalence and mortality rates by disability status using prevalence data on disability from SHARE and mortality data from Eurostat and the Rotterdam Study of Health (ERGO). We use these rates to project future trends of ADL-disability prevalence among the elderly in the Netherlands for the period 2008-2040 using the multistate projection model LIPRO.

\section{RESULTS}

This paper shows that even in the case of limited data, multistate projection models can be applied to project trends in disability prevalence. In a scenario that assumes constant disability incidence rates, disability prevalence among the elderly will increase even though the mortality rates of disabled persons exceed those of non-disabled people. In a

\footnotetext{
${ }^{1}$ Netherlands Interdisciplinary Demographic Institute (NIDI-KNAW)/University of Groningen, the Netherlands. E-Mail: gaag@nidi.nl.

${ }^{2}$ Netherlands Interdisciplinary Demographic Institute (NIDI-KNAW)/University of Groningen, the Netherlands.

${ }^{3}$ Nursing home physician, Stichting Groenhuysen, Roosendaal, the Netherlands.
} 
scenario that assumes declining incidence rates at the same pace as declining mortality rates, disability prevalence will be significantly lower. This latter scenario results in an almost similar decline in disability prevalence as the scenario assuming a strong reduction of age-specific obesity among the elderly. One conclusion, therefore, could be that the prevalence of obesity should be seriously reduced to reach a strong reduction of disability incidence.

\section{CONCLUSIONS}

The strength of this method to calculate disability incidence-rates based on disability prevalence-rates is that the relationship between changes in mortality and changes in disability is taken into account, and that the effects of risk factors can be estimated. The improved transparency of the projections, the generic nature of the model and the applicability to all (European) countries with disability prevalence data make it a useful instrument for making plausible projections of future patterns of disability prevalence based on disability incidence.

\section{Introduction}

In the coming decades, many western European countries will face a strong increase in the number of the elderly, as the large post-war baby boom generations are currently starting to reach the age of 65 . Simultaneously, the number of the oldest old is growing rapidly as a result of increasing longevity (Oeppen and Vaupel 2002). Although different population scenarios for Europe may project different future populations, all scenarios show significant increases in the numbers of the elderly (Eurostat 2008, 2011, 2014; Scherbov, Mamolo, and Lutz 2008; De Beer et al. 2010; Huisman et al. 2013; Rees et al. 2013; United Nations 2014; KC and Lutz 2014). Since health care and longterm care consumption by the elderly, especially by the very old and frail, is well above average, demand of long-term care and health care expenditures are likely to increase significantly (Meerding, Bonneux et al. 1998; Meerding, Polder et al. 1998; Gray 2005; Comas-Herrera et al. 2006; Pavolini and Ranci 2008; Przywara 2010; Rodrigues, Huber, and Lamura 2012). The extent to which this demand will increase depends on the future health status of the elderly population. If the average health status will improve, long-term care need may increase to a lesser extent than the number of elderly persons. On the other hand, if disability increases strongly at very old ages, increasing life expectancies may lead to additional increases in the demand for care. The health status of the elderly is closely related to medical innovations. Improvements in health care may result in better survival, but may extend life in disability. For example, the 
sharp decline in acute coronary heart disease mortality has increased the number of survivors with heart failure (Bonneux et al. 1994; Peeters et al. 2003; Bonneux 2011).

To address policy questions related to the provision of health care services in an ageing population, it is important to know how many people will face disability in very old age. Today, the after-war baby boom cohorts starting in 1946 are reaching old age, making forecasts of the number of disabled elderly even more important for policy makers.

The two main methods used to calculate the future number of disabled elderly are the Sullivan method (Sullivan 1971) and the multistate model (Rogers, Rogers, and Branch 1989). The Sullivan health expectancy reflects the current health of a real population, adjusted for mortality levels and independent of age structure (Jagger, Cox, and Le Roy 2007). This indicator is based on prevalence data and can be used to compare the health status of a population at two points in time, or of two different populations at the same time. Using disability prevalence data, the future number of disabled elderly can be estimated by projecting the future number of elderly persons, and by subsequently multiplying this number by the percentage of the elderly that is expected to be disabled. Disability numbers can be estimated by analyzing past trends in the prevalence of disability and by assuming that these trends will continue in the future. This procedure, however, does not take into account the interaction between changes in mortality and changes in disability. In practice, disability and mortality are related in several ways. First, trends in medical progress that affect mortality may also be expected to affect disability. Second, risk factors that affect both mortality and disability, such as the prevalence of obesity or smoking, may be expected to change over time and may affect mortality and disability in a different way. Finally, mortality rates may differ between non-disabled and disabled persons. In order to take these interdependencies into account in making projections, it is necessary to use a multistate projection model.

Multistate projection models use disability incidence rates to estimate the number of transitions into disability and the number of deaths. A widely used multistate model in epidemiology and medical statistics is the irreversible illness-death model, in which transitions are modelled from the initial healthy state to the absorbing death state, whether or not through the intermediate state of being disabled (Meira-Machado and Roca-Perdinas 2011; Touraine, Gerds, and Joly 2013). The use of multistate models for making scenarios requires that assumptions be made about future changes in disability incidence rates rather than disability prevalence rates. Instead of making assumptions about future proportions of disabled people, one can project these proportions as the result of the underlying transitions. In case of an irreversible illness-death model, i.e., a model without recovery, the future proportion of disabled people at a certain age depends on the probability that non-disabled people will become disabled, and on the 
probabilities that disabled and non-disabled people will die. Another advantage of multistate models is that they can explicitly take into account the effects of changes in risk factors on the prevalence of disability. For instance, if the probability of becoming disabled for obese people exceeds that of people with 'normal' weight, the model can be used to project the effect of changes in the prevalence of obesity on the prevalence of disability.

A disadvantage of the use of multistate models, however, is that the data required for the estimation of transition rates are often missing, or expensive to acquire. This is especially the case for studies aiming at cross-national Europe-wide comparisons. To overcome this disadvantage, we developed a generic estimation procedure for calculating disability incidence rates based on disability prevalence rates. By taking prevalence rates as our point of departure to estimate incidence rates, we also take advantage of the relatively stable patterns of prevalence data compared to the more fluctuating patterns of incidence data (if available at all), while at the same time we can study the impact of different assumptions on transitions into disability.

In the following sections of this paper, we first describe the method for estimating disability incidence rates and mortality rates by disability status, for models with and without risk factors. Then we illustrate the estimation procedure using a multistate model to project future disability prevalence among the elderly, according to two different sets of scenarios of disability incidence for the Netherlands for the period 2008-2040. In the first set we formulate two disability-incidence based scenarios consistent with expansion and compression of morbidity. In the second illustration, we take into account the effect of the obesity risk factor on the onset of disability and on mortality.

\section{Method}

Several papers discuss the estimation of transition rates. A general description is given by Aalen, Borgan and Gjessing (2008), an application in the field of fertility is given by Impicciatore and Billari (2011), and applications in the field of disability are given by for instance Pollard, Golini, and Milella (1990), Jung (2006), and Khoman, Mitchell, and Weale (2008). Calculating disability incidence rates based on disability prevalence rates is not new, either. Different approaches to this problem have been suggested before, for instance, by Podgor and Leske (1986), Keiding (1991), Diamond and McDonald (1992), Barendregt et al. (2003) and Van de Kassteele et al. (2012). Podgor and Leske (1986) and Keiding (1991) identified age-specific incidence under the assumption of time-homogeneous incidence, disease irreversibility and age-specific mortality independent of disease status. Barendregt et al. (2003) developed a generic 
disease development model, DisMod II, which is based on a set of differential equations that describe age specific incidence, remission (recovery) and disease specific mortality. Van de Kassteele et al. (2012) proposed a method to estimate transition probabilities assuming a stationary population and focusing on net transitions between states. Other estimation methods are based on cross-sectional samples in which information is only available on current age and disease status. Diamond and McDonald (1992) provided an excellent survey on using binary regression models to estimate incidence rates from such current status data.

Our estimation method is closely related to the one of Podgor and Leske (1986). Like Podgor and Leske, we consider an irreversible illness-death model with piecewiseconstant (age specific) exponential distributed sojourn times. Furthermore, we both assume a closed population system (i.e., immigration and emigration are ignored) and a stationary population (i.e., prevalence at all ages is static in time). The main advantage of our model, compared to that of Podger and Leske, is that we use a known (total) survival, while they use a known population size. This means that Podger and Leske assume similar mortality risks for people with and without a disease, while we take into account disease-specific mortality based on relative mortality risks. Furthermore, our method allows for additional states based on risk factors, while it is unclear how to incorporate them into the Podgor and Leske method.

Our estimation method is also closely related to the DisMod model developed by Barendregt et al. (2003). They assume that mortality from other causes is independent of the disease specific mortality, while our method takes into account that changes in disease-specific mortality will have an impact on mortality from other causes. Another difference is that they calculate the population at risk using a uniform approximation, while in our model, we use the population at risk directly implied by the (age-specific) exponential transition rates.

An additional asset of our method is that we use a continuous time multistate model, assuming that people can make transitions at any point in time, while a discrete time multistate model as used for instance by Van de Kassteele et al. (2012), only considers transitions at fixed, usually yearly, time points. In other words, discrete time models rule out the possibility that a person could become ill and die from this illness within one time period (a year), while our method also captures very short periods of disability.

\subsection{Estimation of transition rates in an irreversible illness-death model}

The irreversible illness-death model distinguishes three states: non-disabled (nD), disabled (D) and dead, and three possible transitions between these states: disability 
incidence rates: from non-disabled (nD) to disabled (D), and mortality rates for nondisabled and disabled persons: from (nD) to dead and from (D) to dead, respectively (Figure 1).

Figure 1: The irreversible illness-death model

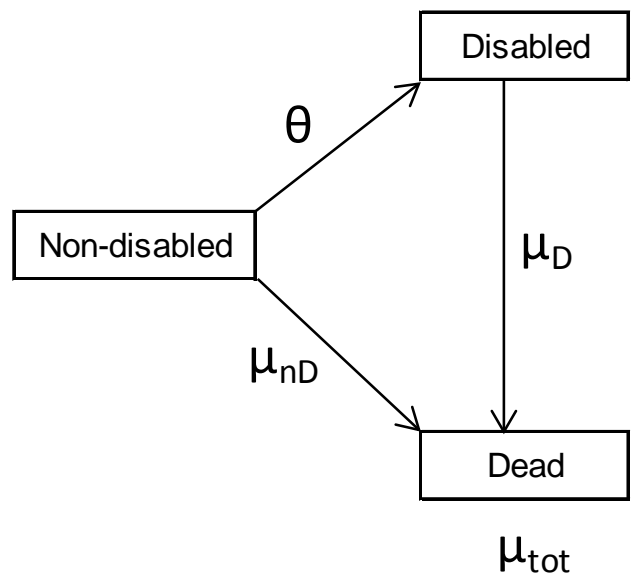

We estimate disability incidence rates from disability prevalence rates in a crosssectional sample combined with mortality rates and relative mortality risks from other sources. A crucial assumption for our method is that the general mortality rate, for the overall population (by sex and age), is known. We extracted these mortality rates from the EUROPOP2008 population projections (Eurostat 2008).

We assume that the observed disability prevalence is the result of a stationary Markov process. Sometimes in continuous multistate models confusion arises between transition rates and transition probabilities. A transition rate, also called a hazard or intensity, is the instantaneous probability that a transition occurs per unit of time, conditional on being at risk just before the transition. A transition probability is the probability of change from one state to another in a given time/age period (usually one year). In a Markov process a one-to-one relationship between the transition rates and the transition probabilities exists. The changes in prevalence are directly related to the transition rates. The estimation procedure is based on this relation.

If we know (a) the total mortality rate $\left(\mu_{\text {tot }}\right)$ at age $x$, (b) the relative mortality risk of disabled persons and (c) the prevalence of disability at age $x$, we can estimate the mortality rate of disabled individuals. We assume that the relative mortality risk of 
disabled individuals versus non-disabled individuals is independent of age, a standard Cox hazard assumption:

$$
\mu_{D}(x)=r_{D}(x) \cdot \mu_{n D}(x)
$$

where $\mu_{D}(x)=$ the mortality rate of disabled persons at age $x, \mu_{n D}(x)=$ the mortality rate of non-disabled individuals at age $x$ and $r_{D}(x)=$ the mortality risk of disabled persons relative to non-disabled individuals at age $x$.

The incidence rate of disability at age $x$ can be estimated from the difference between the prevalence at age $x$ and age $x+1$, taking into account the mortality rate of non-disabled and disabled individuals at age $x$. Thus the estimate of the disability incidence rate depends on the estimate of the mortality of disabled individuals and vice versa. Therefore we use a stepwise iterative procedure.

Step 1: In the first step we calculate the starting value for $\mu_{D}(x)$ from the total death rate and the prevalence of disabled individuals and its complement, the prevalence of non-disabled individuals by solving:

$$
\exp \left(-\mu_{t o t}(x)\right)=Q_{n D}(x) \exp \left(-\mu_{n D}(x)\right)+Q_{D}(x) \exp \left(-r_{D}(x) \mu_{n D}(x)\right)
$$

where $\mu_{\text {tot }}(x)=$ the total (overall) mortality rate at age $x, Q_{n D}(x)=$ the proportion of nondisabled individuals at age $x$ and $Q_{D}(x)=$ the proportion of disabled individuals. Since we assume an exponential model for the age pattern of mortality, $\exp (-\mu(x))$ equals the probability to survive from age $x$ to $x+1$.

Step 2: In the second step we calculate the value of the disability incidence rate $\theta(x)$, i.e., the transition rate from non-disabled to disabled between ages $x$ and age $x+1$ in such a way that the projected prevalence at age $x+1$ equals the observed prevalence. Assuming a stationary population the disability prevalence at age $x+1$, of those who survive till age $x+1$, can be calculated by the sum of the product of the non-disability prevalence at age $x$ and the probability of non-disabled individuals to survive and become disabled, $P_{n D, D}(x)$, and the product of disability prevalence at age $x$ and the probability of a disabled individual at age $x$ to survive and remain disabled till age $x+1$, $P_{D, D}(x)$. Because some individuals die between age $x$ and $x+1$, with probability 1- $P_{n D, D}(x)-P_{n D, n D}(x)$ for the non-disabled and with probability 1- $P_{D, D}(x)$ for the disabled, the disability prevalence at age $x+1$ is conditional on survival. Thus:

$$
\hat{Q}_{D}(x+1)=\left[Q_{n D}(x) P_{n D, D}(x)+Q_{D}(x) P_{D, D}(x)\right] / S(x)
$$


where $\hat{Q}_{D}(x+1)=$ the projected prevalence of disability at age $x+1$ and $S(x)=$ the survival of all individuals from age $x$ to age $x+1$ (the non-disabled either remain nondisabled or become disabled and the disabled remain disabled):

$$
S(x)=Q_{n D}(x)\left[P_{n D, n D}(x)+P_{n D, D}(x)\right]+Q_{D}(x)\left[P_{D, D}(x)\right]
$$

The transition probabilities at age $x$ can be calculated from the transition rates using a singular value decomposition of the matrix of transition probabilities: $P(x)=\exp (M(x))=V(x) H(x) V(x)^{-1}$, with $M(x)$ is the matrix of transition rates, $V(x)$ is the matrix of eigenvectors of $M(x)$, and $H(x)$ is the exponentiated matrix of eigenvalues ${ }^{4}$. Because death is an absorbing state one eigenvalue is zero. The other, non-zero, eigenvalues are denoted by $\lambda$ and $\varphi$ (also age-specific). Then $H(x)$ is a diagonal matrix with on the diagonal $\left(e^{\lambda}, e^{\varphi}, 1\right)$. In an illness-death model without recovery the transition probabilities have an analytical solution (see e.g., Singer and Spilerman 1976). The three relevant transition probabilities in an illness-death model are first the probability of disabled individuals at age $x$ to be disabled at age $x+1$, which equals their survival probability:

$$
P_{D, D}(x)=\exp \left[-\mu_{D}(x)\right]
$$

Second, the probability of non-disabled individuals at age $x$ remaining nondisabled until age $x+1$, which is equal to the product of the probability of remaining non-disabled, $\exp (-\theta(x))$, and the probability of survival $\exp \left(-\mu_{n D}(x)\right)$ :

$$
P_{n D, n D}(x)=\exp \left[-\theta(x)-\mu_{n D}(x)\right]
$$

And third, the probability of survival and transition from non-disabled to disabled can be derived from the singular value decomposition or directly from the probability of surviving and becoming disabled at $x+1$ conditional on being non-disabled at $x$ :

$$
\begin{aligned}
P_{n D, D}(x) & =\theta(x) \exp \left(-\mu_{D}(x)\right) \int_{0}^{1} \exp \left(-\left(\mu_{n D}(x)+\theta(x)-\mu_{D}(x)\right) y\right) d y \\
& =\frac{\theta(x)}{\mu_{n D}(x)+\theta(x)-\mu_{D}(x)}\left\{\exp \left[-\mu_{D}(x)\right]-\exp \left[-\theta(x)-\mu_{n D}(x)\right]\right\}
\end{aligned}
$$

\footnotetext{
${ }^{4}$ In the multistate demographic literature the matrix of transition rates is defined as minus the transpose of the matrix of transition rates as defined in econometrics and biostatistics we used here. Then $P(x)=\exp (-M(x))$.
} 
This probability depends on both the transition rate from non-disabled to disabled and on the mortality rates of both disabled and non-disabled individuals.

We calculate the value of $\theta(x)$ for which the projected value of the prevalence equals the observed value, i.e., $\hat{Q}_{D}(x+1)=Q_{D}(x+1)$ given the estimated starting value of $\mu_{D}(x)$ (and $\mu_{n D}(x)$ ).

Step 3: In the third step we recalculate $\mu_{D}(x)$ such that the projected mortality of disabled and non-disabled persons equals total mortality using equation (4) with $S(x)=\exp \left(-\mu_{t o t}(x)\right)$.

We repeat steps 2 and 3 until we reach convergence.

\subsection{Adding the risk factor obesity}

To illustrate how to include the effect of risk factors in the model, we extend the 3-state model to a 5-state model including the risk factor 'obesity status'. Obesity, i.e., a body mass index (BMI) greater than or equal to 30, increases the risk of disability often just by putting more weight on joints. Other obesity comorbidities include, for instance, coronary heart disease, hypertension and stroke, diabetes, and certain types of cancer. Adding obesity to the model results in the following five states: non-obese, nondisabled (nOnD), obese, non-disabled (OnD), non-obese, disabled (nOD), obese, disabled (OD) and dead. The number of transitions included in the model will depend on whether all theoretically possible transitions have to be taken into account. For practical purposes, the number of transitions may be reduced, e.g., because reliable data are lacking or because specific transitions are assumed to be very low. In this paper we distinguish six transitions: transitions into disability for non-obese and obese persons and to death for non-obese and obese persons whether or not being disabled. When no transitions between the obese and non-obese groups exist, the method from the previous section can be extended to estimate the disability incidence and mortality rates. Note that the groups are still connected through the mortality rate, because we only assume to know the overall (age-specific) mortality and the relative mortality risks (Figure 2). 
Figure 2: The irreversible illness-death model including risk factor obesity

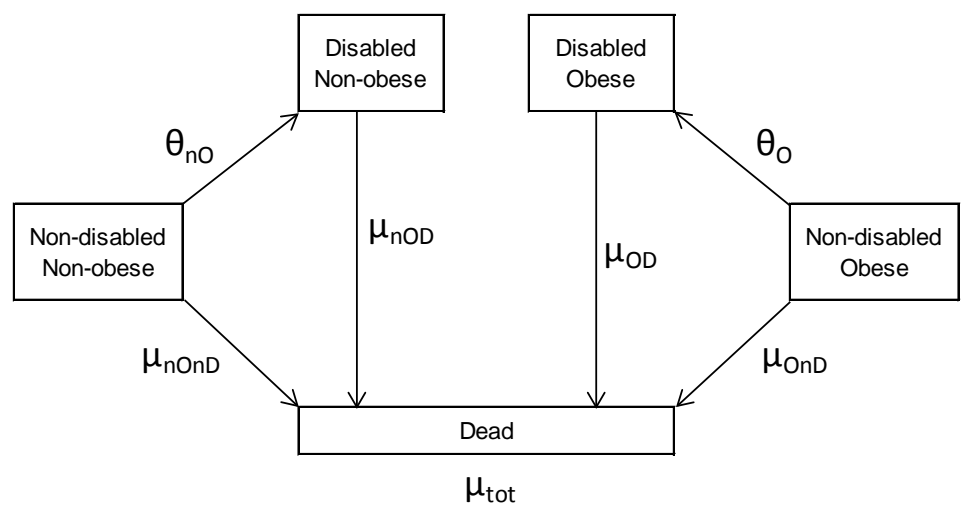

For example, if obese individuals have, independent of disability status, a higher mortality risk, the prevalence of obese individuals in the population alive declines with increasing age. Disability incidence and mortality from the basic illness-death model are a weighted average of these transition rates by obesity status, with as weights the relative disability prevalence.

To estimate obesity-specific incidence and mortality rates we need the relative mortality risk $r_{O}(x)$ and the relative disability incidence rate $i_{O}(x)$ of individuals with obesity compared to those without obesity. Thus

$$
\mu_{O D}(x)=r_{O}(x) \cdot \mu_{n O D}(x)
$$

where $\mu_{O D}(x)=$ the mortality rate of disabled persons with obesity at age $x$ and $\mu_{n O D}(x)=$ the mortality rate of disabled individuals without obesity, and we assume

$$
\theta_{O}(x)=i_{O}(x) \cdot \theta_{n O}(x)
$$

where $\theta_{O}(x)=$ the disability incidence rate of obese individuals from age $x$ to $x+1$ and $\theta_{n O}(x)=$ the disability incidence rate of non-obese individuals.

The mortality rate of a non-obese disabled individual, $\mu_{n O D}(x)$, can be obtained from equating the survival of disabled individuals to the weighted survival of obese and non-obese disabled individuals:

$$
\begin{aligned}
\exp \left(-\mu_{D}(x)\right)= & \frac{Q_{O D}(x)}{\frac{Q_{O D}(x)+Q_{n O D}(x)}{Q_{n O D}(x)}} \exp \left(-r_{O}(x) \cdot \mu_{n O D}(x)\right)+ \\
& \exp \left(-\mu_{n O D}(x)\right)
\end{aligned}
$$


where $Q_{O D}(x)=$ the prevalence of disabled obese individuals at age $x$ and $Q_{n O D}(x)=$ the prevalence of non-obese disabled individuals. Thus, the weight $Q_{O D}(x) /\left(Q_{O D}(x)+Q_{n O D}(x)\right)$ is the proportion obese among the disabled individuals at age $x$.

The survival of non-disabled individuals is also a weighted average of the survival of obese and non-obese non-disabled individuals and the mortality rate of a non-obese non-disabled individual, $\mu_{n O n D}(x)$, can be obtained from solving:

$$
\begin{aligned}
\exp \left(-\mu_{n D}(x)\right)= & \frac{Q_{O n D}(x)}{Q_{O n D}(x)+Q_{n O n D}(x)} \exp \left(-r_{O}(x) \cdot \mu_{n O n D}(x)\right)+ \\
& \frac{Q_{n O n D}(x)}{Q_{O n D}(x)+Q_{n O n D}(x)} \exp \left(-\mu_{n O n D}(x)\right)
\end{aligned}
$$

where $Q_{O n D}(x)=$ the prevalence of non-disabled obese individuals at age $\mathrm{x}$ and $Q_{n O n D}(x)=$ the prevalence of non-obese non-disabled individuals and $Q_{O n D}(x) /\left(Q_{O n D}(x)+Q_{n O n D}(x)\right)=$ the proportion obese among the non-disabled at age $x$.

Finally, the probability to remain non-disabled is also a weighted average of the probability to remain non-disabled of obese and non-obese individuals and the disability incidence rate of a non-obese individual, $\theta_{O}(x)$, can be obtained from solving :

$$
\begin{aligned}
\exp (-\theta(x))= & {\left[Q_{O D}(x)+Q_{O n D}(x)\right] \exp \left(-i_{O}(x) \cdot \theta_{O}(x)\right)+} \\
& {\left[Q_{n O D}(x)+Q_{n O n D}(x)\right] \exp \left(-\theta_{n O}(x)\right) }
\end{aligned}
$$

\section{Two illustrations of disability incidence based scenarios}

To illustrate the possibility of applying a multistate model with limited data only, we project the future prevalence of disabled elderly based on two different sets of scenarios of disability incidence for the Netherlands, one without risk factors and one with the risk factor obesity. In these scenarios disability refers to ADL-disability as defined by Katz et al. (1963): having at least one disability in basic activities of daily living (ADL): getting out of bed, dressing, washing, going independently to the toilet and eating without help. As, for the elderly, becoming disabled generally is a progressive process, we estimate an irreversible illness-death model and exclude recovery from disability from the model.

Since we focus on the elderly aged 65 and over, we do not have to compile projections from birth onwards. In order to take into account changes in obesity prevalence at age 55, our projections start at age 55 and run to age $100+$. The population for the first age group (age 55) was extracted from the EUROPOP2008 population projections (Eurostat 2008). As a result, we implicitly introduce the 
mortality and migration assumptions at ages younger than 55 of the EUROPOP2008 scenarios. As our scenarios cover the period 2008-2040, our projections are based on the population already alive. Therefore, the model does not need to include fertility. Moreover, since both immigration and emigration rates tend to be low for elderly people migration is excluded from the model as well. Thus, contrary to EUROPOP2008, we use a life table model of a closed population. As a consequence, the results of our projections of the population aged 65+ will be slightly different from the EUROPOP2008 results.

We first estimate disability incidence rates and mortality rates for disabled and non-disabled persons using the method described in section 2. Subsequently, we use these rates to project future numbers of disabled and non-disabled persons according to different scenarios on disability incidence using the multistate demographic projection model LIPRO (Van Imhoff and Keilman 1991). From these projections we calculate the future disability prevalence consistent with the different assumptions on disability incidence. As our aim is to illustrate possible changes in disability prevalence due to different developments in disability incidence rather than to project the most likely future number of disabled elderly, we focus on trends in disability prevalence among the elderly instead of absolute numbers of disabled persons aged 65+.

\subsection{Estimates of disability incidence based on disability prevalence in the Netherlands}

To determine the age and sex specific prevalence of disability in the Netherlands, we used data on the prevalence of disability from the Survey of Health, Ageing and Retirement in Europe (SHARE). We used a Gompertz model with 3 parameters ${ }^{5}$ to smooth the age pattern of the observed prevalence rates, using the number of observations by age as weights. A drawback of using SHARE data is that these data do not include people living in institutions. In the Netherlands a considerable proportion of the oldest old is institutionalized. Since for most of these people being ADL-disabled is the reason why they could not stay in a private house, data excluding people living in institutions will lead to underestimating the prevalence of disability among the elderly. Therefore, we increased the SHARE estimate by age specific factors based on administrative data on persons who receive financial support for long-term care expenses (AWBZ data). Even though most of these expenses cover the costs for the institutionalized population, not all elderly persons living in institutions are ADLdisabled. The factors we used to raise the age and sex-specific SHARE estimates are based on the percentages of the institutionalized population with ADL-limitations. The

\footnotetext{
${ }^{5}$ b1*exp(-exp(-b2*age-b3))
} 
resulting smoothed age patterns of ADL-disability prevalence estimates for males and females are given in Figure 3.

Figure 3: Disability prevalence by gender, the Netherlands 2008

\section{Prevalence}

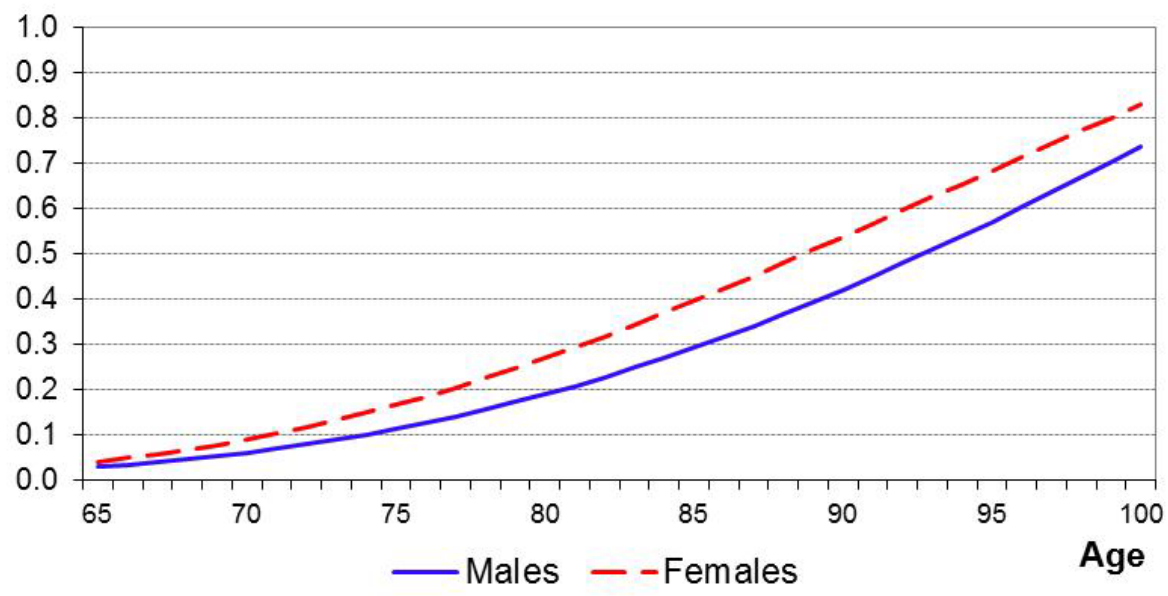

Applying these prevalence rates to the Dutch population as of 1 January 2008 results in an estimate of slightly over 400 thousand elderly with ADL-disability. This is consistent with other estimates of Dutch elderly in need of ADL-care around 2008 (Ageing Working Group 2009; Mot et al. 2010). To estimate the relative mortality risks of disabled persons we used a Cox proportional hazards model based on data from the Rotterdam study of health ERGO (Hu et al. 2005). The estimated relative mortality risk of disabled persons relative to non-disabled persons equals 1.89 for men and 1.55 for women.

The solid lines in Figure 4 show the estimated incidence rates for men and women in the Netherlands in 2008. Although disability prevalence of females surpasses that of males at all ages, differences in incidence between men and women are only minor, and incidence rates of women exceed that of men only up to the age of 80 . 
Figure 4: Disability incidence, the Netherlands 2008 and 2040 Incidence Males

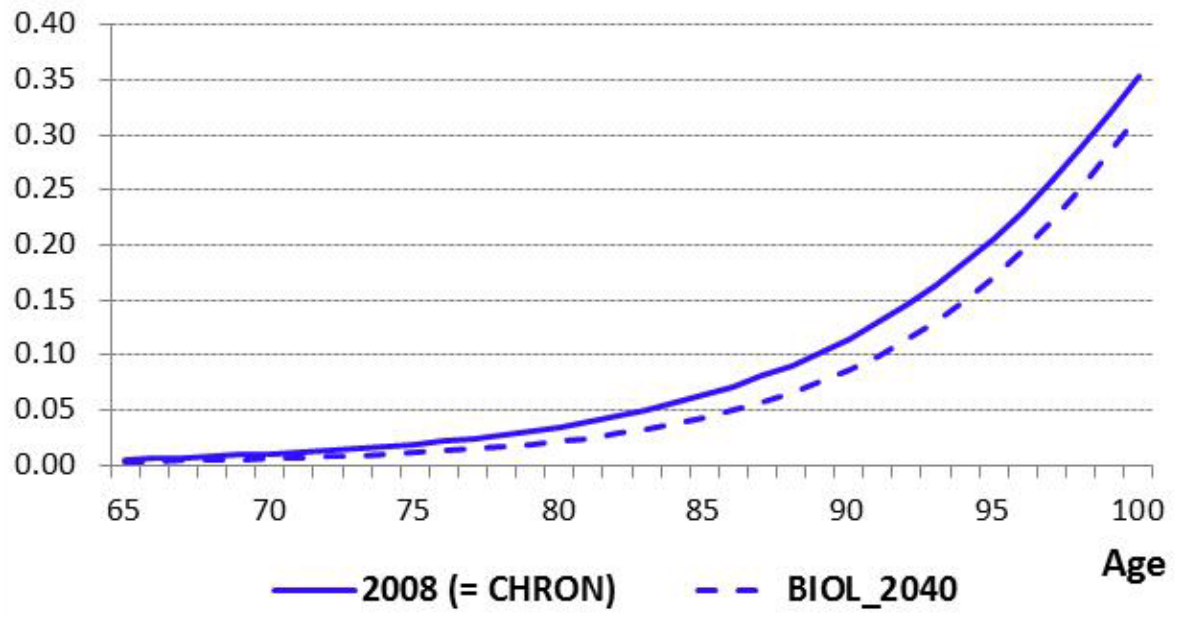

Incidence

Females

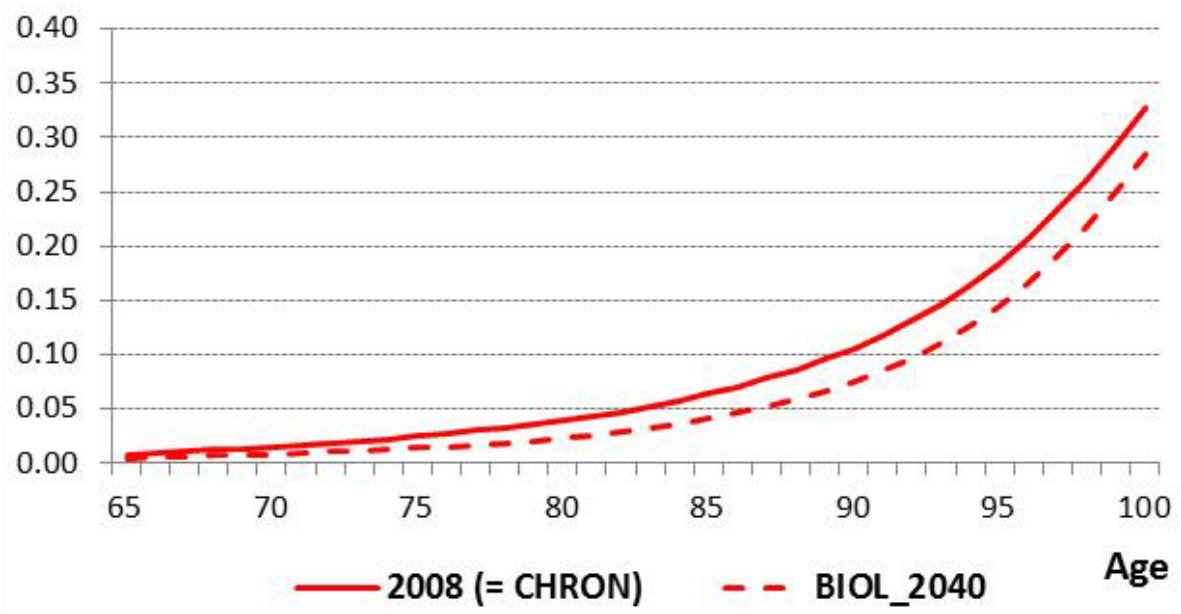




\subsection{Expansion or compression of disability}

For making scenarios we need to make assumptions about the future values of mortality rates conditional on disability status and about the transition rates from being nondisabled to disabled. For the mortality rates we assume a similar decline for both nondisabled and disabled persons as in the EUROPOP2008 mortality projections. For morbidity, we formulate alternative assumptions about future changes in disability incidence rates for the period 2008-2040, distinguishing two different scenarios based on either expansion or compression of morbidity.

A long standing debate on compression or expansion of morbidity has been started with the seminal paper of James Fries on compression of morbidity (Fries 1980). Recent analyses confirm an extended life free of care and in good health (Manton, Gu, and Lowrimore 2008), but which goes together with increased care-dependent life, as the incidence of care is strongly age dependent (Olshansky et al. 1991). Both disability and mortality at old age are strongly related processes, determined by increasing frailty, a consequence of ageing (Mitnitski et al. 2002). In recent periods, life expectancy is increasing by decreasing mortality of the elderly (Christensen et al. 2009; Vaupel 2010). Changes in disability confirm a longer life in good health of elderly (Cai and Lubitz 2007; Manton, Gu, and Lowrimore 2008). Wear and tear is a chronological process, depending on duration of exposure, but repair and other plastic responses to damage by wear and tear are biological processes, which may be supported by healthy lifestyles and medical technology (Christensen et al. 2009).

In the first scenario, we keep the disability incidence rates constant over the entire projection period. This shows the net consequences of mortality decrease if incidence stays put at a certain age and may be called a chronological scenario, as it assumes that incidence of disability is determined by the chronological time spent in the life course (the scenario CHRON). Old age mortality moves further up to increasing ages, but incidence of old age disability stays constant at the same age. The chronological scenario is consistent with expansion of morbidity.

The second scenario (the scenario BIOL) is a theoretical scenario assuming that the biological process of dying at old age is intimately related to the process of senescent disability. This scenario assumes that the incidence of disability and mortality are caused by the same biological ageing process (Mitnitski et al. 2002). When old age mortality is postponed to increasing ages, incidence of old age disability is postponed similarly. There is increasing empirical evidence to support this biological hypothesis (Vaupel 2010). In this scenario we assume that incidence rates decrease at the same pace as mortality rates. This scenario is consistent with compression of morbidity, and predicts the expansion of healthy life without expansion of disabled life years. The dotted lines in Figure 4 show the age-specific disability incidence rates in the BIOL 
scenario for 2040. Compared to the solid lines, the dotted lines show how the incidence rates in the biological scenario decline over time.

\subsection{Life expectancy at age 65}

Using life table techniques we can calculate the remaining life expectancy at age 65 for both people with and without disability and compare these estimates with the remaining life expectancy at age 65 based on the EUROPOP2008 mortality rates. Table 1 shows that our estimates of life expectancy including expected duration of disability, succeed well in reproducing the EUROPOP life expectancies for 2008. For the Netherlands, the life expectancy is 19.9 years for women and 16.6 years for men. Males will spend 2.2 years with ADL-disability, while females will live almost twice as long with disability, which is consistent with the higher disability prevalence among women compared to men.

Table 1: Life expectancy at age 65, the Netherlands

\begin{tabular}{lccc}
\hline & \multicolumn{3}{c}{ Life expectancy at age 65 } \\
\cline { 2 - 4 } & Total & Non-disabled & Disabled \\
\hline Females & & & \\
2008 & 19.9 & 15.6 & 4.3 \\
2008 EUROPOP2008 & 19.9 & & \\
2040 CHRON & 23.1 & 17.3 & 4.8 \\
2040 BIOL & 23.4 & 19.0 & \\
2040 EUROPOP2008 & 23.1 & & 2.2 \\
Males & & & \\
2008 & 16.6 & 14.4 & 2.3 \\
2008 EUROPOP2008 & 16.6 & & \\
2040 CHRON & 19.8 & 16.5 & \\
2040 BIOL & 20.1 & 17.6 & \\
2040 EUROPOP2008 & 19.8 & & \\
\hline
\end{tabular}

Looking at projections for 2040, the expansion of morbidity scenario (CHRON) results in additional years with disability. In this scenario, disabled people will live with disability longer, as decreasing mortality extends their survival. As mortality risks of non-disabled persons will decline too, also non-disabled people will live longer. In relative terms, however, the increase in remaining life expectancy with disability will be larger than the increase in years without disability as the decline of the higher mortality 
rates in the disabled state adds to the projected life expectancy more than a relatively similar decline of the lower mortality rates in the non-disabled state.

When introducing the intermediate state of disability, the projected life expectancy may differ from the EUROPOP scenarios. This is the case for the compression of morbidity scenario (BIOL), although the differences with EUROPOP are small. Compared to 2008, the BIOL scenario adds only little time with disability as it not only assumes declines in mortality, but also in disability incidence. In this scenario the additional years are mainly years without disability.

\subsection{Trends in disability}

Figure 5 shows the consequences of the changes in incidence and mortality in terms of changes in age-specific disability prevalence. Compared to 2008, by 2040 disability prevalence in all 5-year age groups will be slightly higher if disability incidence will not change (scenario CHRON). This scenario shows that if disability incidence rates would remain the same, the decline of mortality rates will result in an increase of the percentage of disabled persons, even though the mortality rates of disabled persons exceed those of non-disabled people. The biological scenario (BIOL) significantly lowers the estimates of ADL-disability prevalence. Thus if incidence rates decrease similar to mortality rates, the future number of disabled elderly will increase less strongly than the increase in the total number of elderly people.

Figure 5: Disability prevalence by age, the Netherlands 2008 and 2040

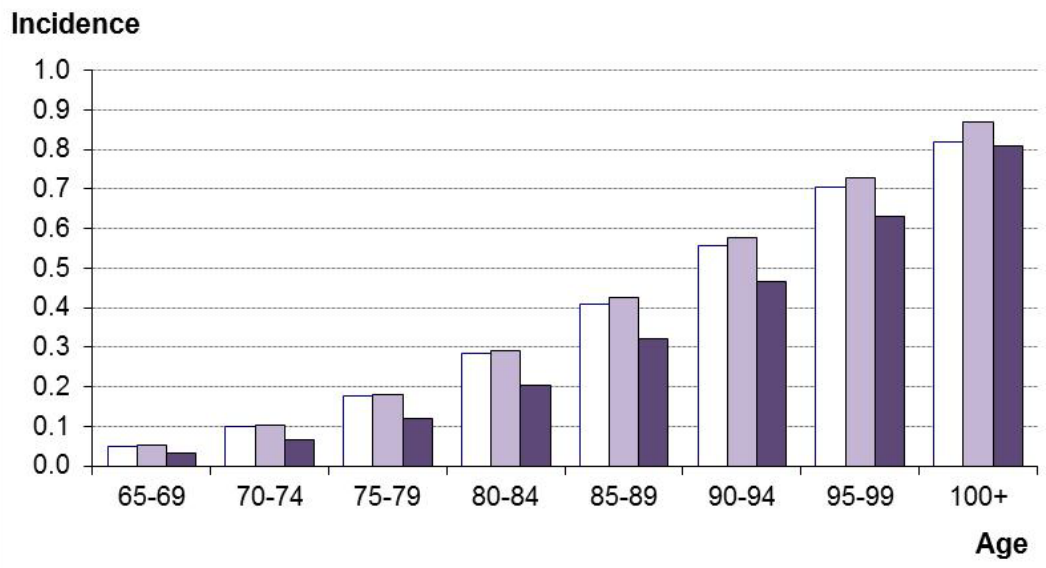

$\square 2008 \square$ CHRON2040 $\square$ BIOL2040 
Overall disability prevalence among the age group 65+ will be lower in all projection years in the biological scenario with a maximum reduction of 12 per cent compared to 2008 in the mid-2030s. In the chronological scenario disability prevalence of the elderly will decline in the short term, but will increase almost linearly from 2016 onwards to an increase of almost 20 per cent by 2040 (Figure 6). This short term decline is the combined effect of declining mortality rates which results in more survival among the elderly, together with the baby boom generations reaching the age of 65, resulting initially in a lower average age in the age group 65+.

Figure 6: Trends in disability prevalence of the elderly (65+), the Netherlands Index prevalence 2008=100

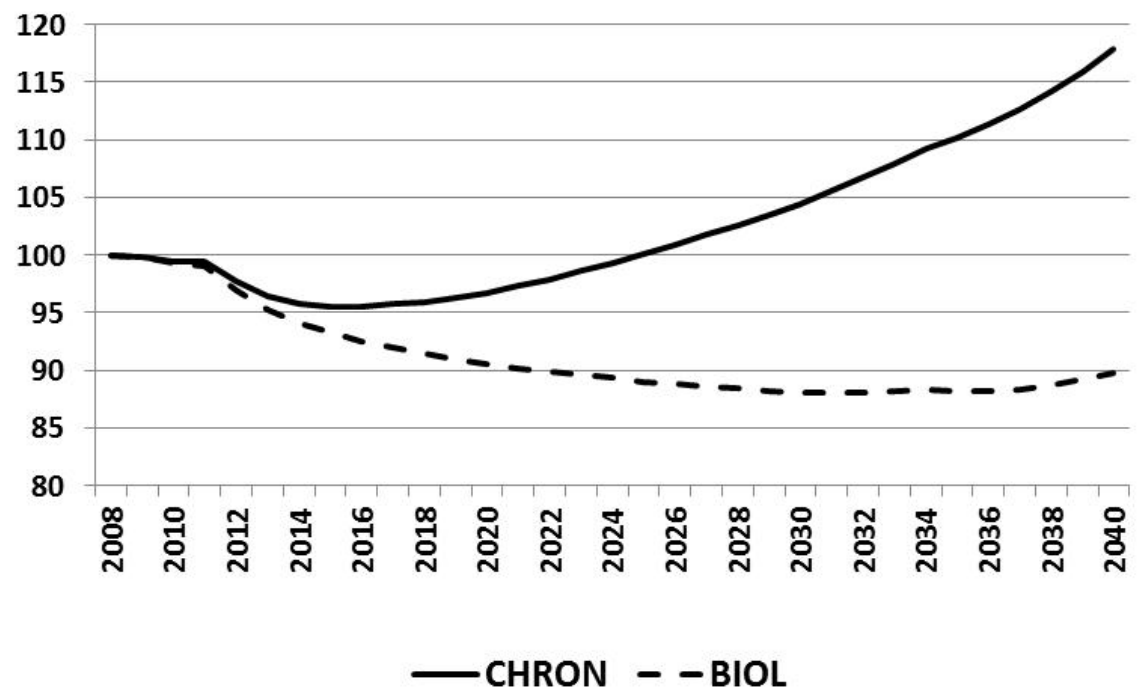

\subsection{The impact of obesity}

To illustrate the inclusion of risk factors in the model, we calculated a second set of scenarios taking into account the impact of obesity. For these scenarios we assume that obesity status at age 55 determines the risks of disability and mortality later in life. Note that this does not imply that we assume that obesity status does not change with age. Measuring obesity at higher ages, however, is complicated and the effect of obesity on morbidity and mortality is more complex in old age (Cetin and Nasr 2014). For people 
over age 75, for instance, the relative risk of death has been found to decrease with increasing BMI (Oreopoulos et al. 2009). Another confounding effect is reverse causality, i.e., disabled persons will not be able to be physically active and may become obese because they are disabled (Wannamethee et al. 2000; Han, Tajar, and Lean 2011). This may play a part especially later in life. Furthermore, if persons lose height as a result of vertebral compression fractures, his or her BMI will become higher, even with no change in weight (Horani and Mooradian 2002), while persons may not be recognized as obese if they gain fat which remains unnoticed as they simultaneously lose muscle weight, which also is related to ageing (Roubenoff 2004). For these reasons, at higher ages, the group of people with low BMI includes persons who have always been lean and at the same time persons that lost weight through illness or persons that may have health problems similar to those with too much weight, but that are not classified as obese. Furthermore, elderly people who became obese at younger ages have greater risks of osteoarthritis, which can cause disability and physical impairment (Felson et al. 1988; Losina et al. 2011). Therefore, we assume that obesity status at age 55 determines the risks of ADL-disability and mortality later in life and we did not include changes in obesity status after the age of 55 in our models. This assumption, however, may under- or overestimate the population at risk of disability at older ages. To gain a better understanding of the relationship between obesity and disability prevalence, therefore, we added two scenarios taking into account significantly decreasing or increasing prevalence of obesity at age 55 .

In the obesity scenarios we divide the population at age 55 in the groups "obese" and "non-obese" and project the numbers of disabled and non-disabled elderly for both groups separately. The obesity scenarios are consistent with the biological scenario; that means that also for the obesity scenarios, we assume that disability incidence rates decrease to a similar extent as mortality rates do. In the first obesity scenario we assume that the prevalence of obesity at age 55 moves forward to older ages. This so-called BMI-scenario shows the impact of current obesity trends on disability prevalence given a general decline of disability incidence. In the second obesity scenario we assume that the prevalence of obesity will return to the much lower levels of the 1960s. This would imply that the prevalence of obesity at age 55 would be about half of that in the BMIscenario. This back-to-leaner populations scenario (LEAN) is an optimistic scenario as we assume that this halving of obesity prevalence happens immediately in 2008. The third obesity scenario is a pessimistic one, assuming an acceleration of the obesity epidemic with an instant jump to levels more or less observed in the United States, i.e., a doubling of the prevalence of obesity at age 55 from 2008 onwards (FAT).

To estimate obesity-specific ADL-disability incidence and mortality we need data on obesity-specific ADL-disability prevalence and mortality rates for persons with and without ADL-disability (as estimated in the model without obesity). Although SHARE 
covers data on both ADL-disability and obesity prevalence the numbers are too small to directly infer obesity-specific ADL-disability prevalence from this survey. Therefore we estimated obesity-specific ADL-disability prevalence from the marginal prevalence of ADL-disability and obesity based on SHARE data, using the Mantel-Haenszel method to calculate the odds ratio (OR). The Mantel-Haenszel method provides a pooled odds ratio for several strata, in this case age groups and countries ${ }^{6}$, assuming a fixed effects model. The OR shows the ratio of the odds of being disabled while being obese $(\mathrm{OD} / \mathrm{OnD})$ to the odds of being disabled and being not obese (nOD/nOnD). For males the odds ratio ([OD/OnD]/[nOD/nOnD]) turned out to be not significant different from 1, while for females the ratio was highly significant. Therefore we assume that ADL-disability in the base population of 2008 is relatively equally found among obese and non-obese males (odds ratio of 1 ), and is more likely to occur among obese than non-obese women by a factor of slightly over 2 (odds ratio of 2.1). Since the odds ratio is a function of the four cells of the obesity-specific ADL-disability prevalence matrix (OD, OnD, nOD, and nOnD), for both sexes and all ages the four cell prevalences can be recovered from the marginal prevalences of ADL-disability ( $\mathrm{D}$ and $\mathrm{nD}$ ) and obesity ( $\mathrm{O}$ and $\mathrm{nO}$ ) and the Mantel-Haenszel odds ratio.

Obesity-specific incidence and mortality is estimated such that the weighted average is equal to the total incidence and total mortality using as weights the disability prevalence for the obese and the non-obese and using the relative mortality risk for obesity based on a study of Walter et al. (2009). Walter et al. (2009) estimated adjusted hazard ratios for mortality stratified by disability status for four BMI categories for the population of the Netherlands aged 55+ for calendar year 2008: normal weight (BMI 18.5-25), overweight (BMI 25-30), obesity I (BMI 30-35) and obesity II/III (BMI $35+$ ). We calculated the relative mortality risks for obese persons as the ratio of the weighted average of the relative risks of Walter et al. for BMI 30-35 and BMI 35+ to the weighted average of the relative risks of Walter et al. for BMI 18.5-25 and BMI 25-30, with the prevalence of the different BMI categories as weights. Similar weights are assumed for males and females. The relative mortality risks by gender and obesity status are given in Table 2 .

\footnotetext{
${ }^{6}$ In this paper we only present the results for the Netherlands, but apart from the Netherlands also Germany, Spain and Poland were part of the study (see Bonneux et al. 2012).
} 
Table 2: Obesity-specific mortality

\begin{tabular}{|c|c|c|c|c|c|c|c|c|c|c|c|}
\hline \multicolumn{12}{|c|}{ Relative mortality risks (RR) by ADL-disability and obesity } \\
\hline & \multicolumn{2}{|c|}{$\begin{array}{c}\text { RR mort by } \\
\text { gender (ERGO) }\end{array}$} & & \multicolumn{2}{|c|}{$\begin{array}{c}\text { RR mort by } \\
\text { obesity (Walter) }\end{array}$} & & \multicolumn{5}{|c|}{$\begin{array}{l}\text { RR mort by gender and obesity } \\
\text { (ERGOxWalter) }\end{array}$} \\
\hline & \multirow[b]{2}{*}{ males } & \multirow[b]{2}{*}{ females } & & \multirow[b]{2}{*}{ no } & \multirow[b]{2}{*}{$\mathbf{O}$} & & \multicolumn{2}{|c|}{ males } & & \multicolumn{2}{|c|}{ females } \\
\hline & & & & & & & no & 0 & & no & $\mathbf{0}$ \\
\hline $\mathrm{nD}$ & 1 & 1 & $\mathrm{nD}$ & 1 & 1.11 & $\mathrm{nD}$ & 1 & 1.11 & $\mathrm{nD}$ & 1 & 1.11 \\
\hline D & 1.89 & 1.55 & D & 1 & 0.91 & D & 1.89 & 1.72 & D & 1.55 & 1.41 \\
\hline
\end{tabular}

The resulted obesity-specific incidence rates are given in Figure 7. Both among women and men, the incidence of ADL-disability among the obese is higher than among the non-obese. For mortality, on the other hand, rates among non-obese persons are higher for disabled than for non-disabled persons, while among obese persons the reverse is true (see Figure 8). The higher incidence risk for obese people together with mitigated mortality rates for the obese once disabled, are consistent with the literature: “smoking kills, obesity disables” (Reuser, Bonneux, and Willekens 2008, 2009; Majer et al. 2011).

Figure 9 shows the effects of the three obesity scenarios on disability prevalence. Note that the assumptions on obesity will affect disability among the elderly aged 65 and over only from 2018 onwards. This figure shows that assuming current obesity levels to remain constant in the future (scenario BMI) will result in a smaller decline of disability prevalence compared to the biological scenario where we assume a strong reduction of age-specific disability incidence resulting in compression of morbidity. The results of the scenario assuming a strong reduction of age-specific obesity among the elderly (scenario LEAN) are highly similar to the biological scenario. Therefore, one conclusion could be that the prevalence of obesity should be seriously reduced to reach a strong reduction of disability incidence. Alternatively we could conclude that a strong reduction of disability incidence, as assumed in the biological scenario, is too optimistic given current patterns of obesity. If obesity levels at age 55 double in 2008, the decline in disability prevalence among the 65 plus due to declining incidence in the first ten years of the projection period will be almost completely counterbalanced by the increase in obesity in the period 2020-2040. 
Figure 7: $\quad$ Incidence conditional on obesity, the Netherlands 2008

\section{Incidence}

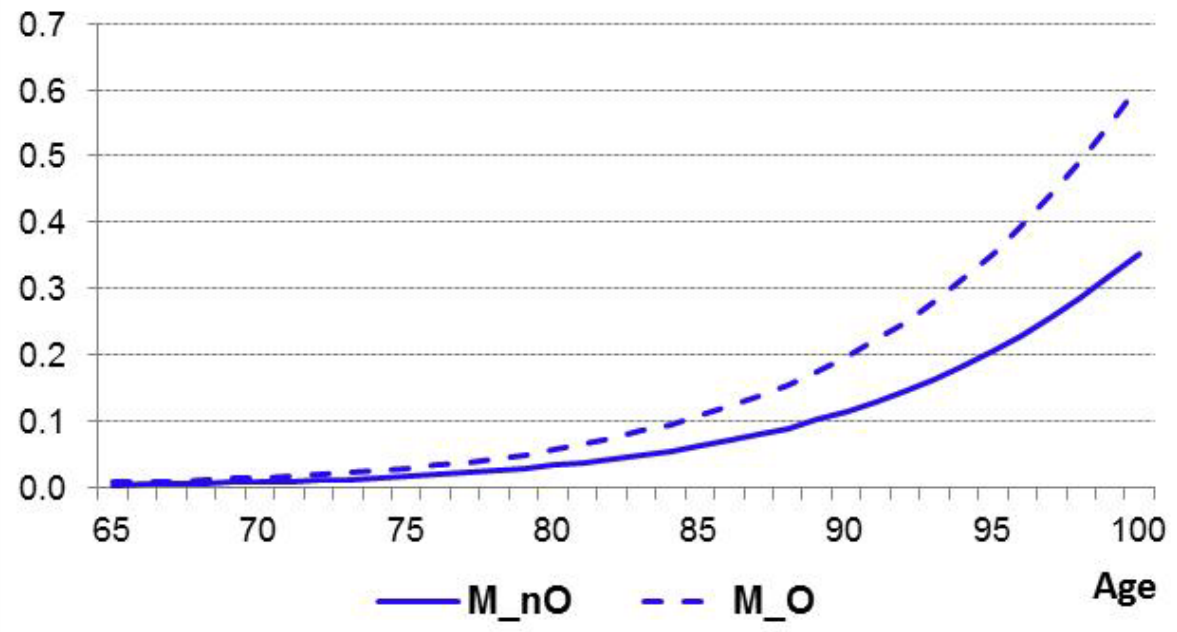

Incidence

Females

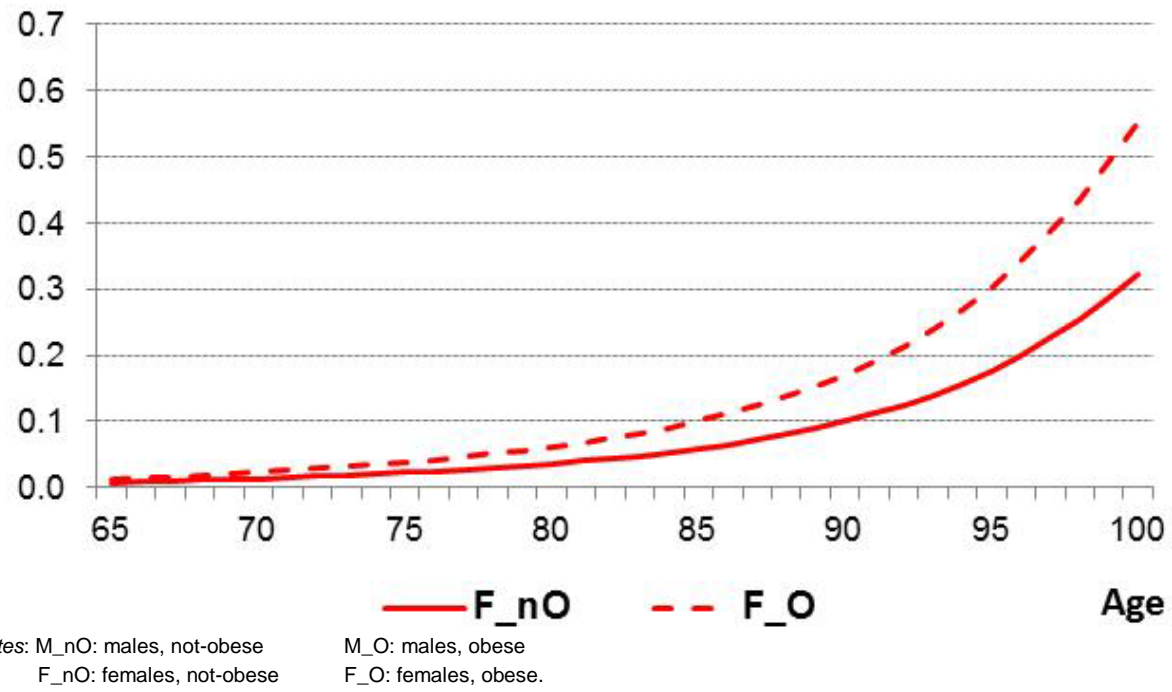


Figure 8: Mortality conditional on obesity and disability, the Netherlands 2008
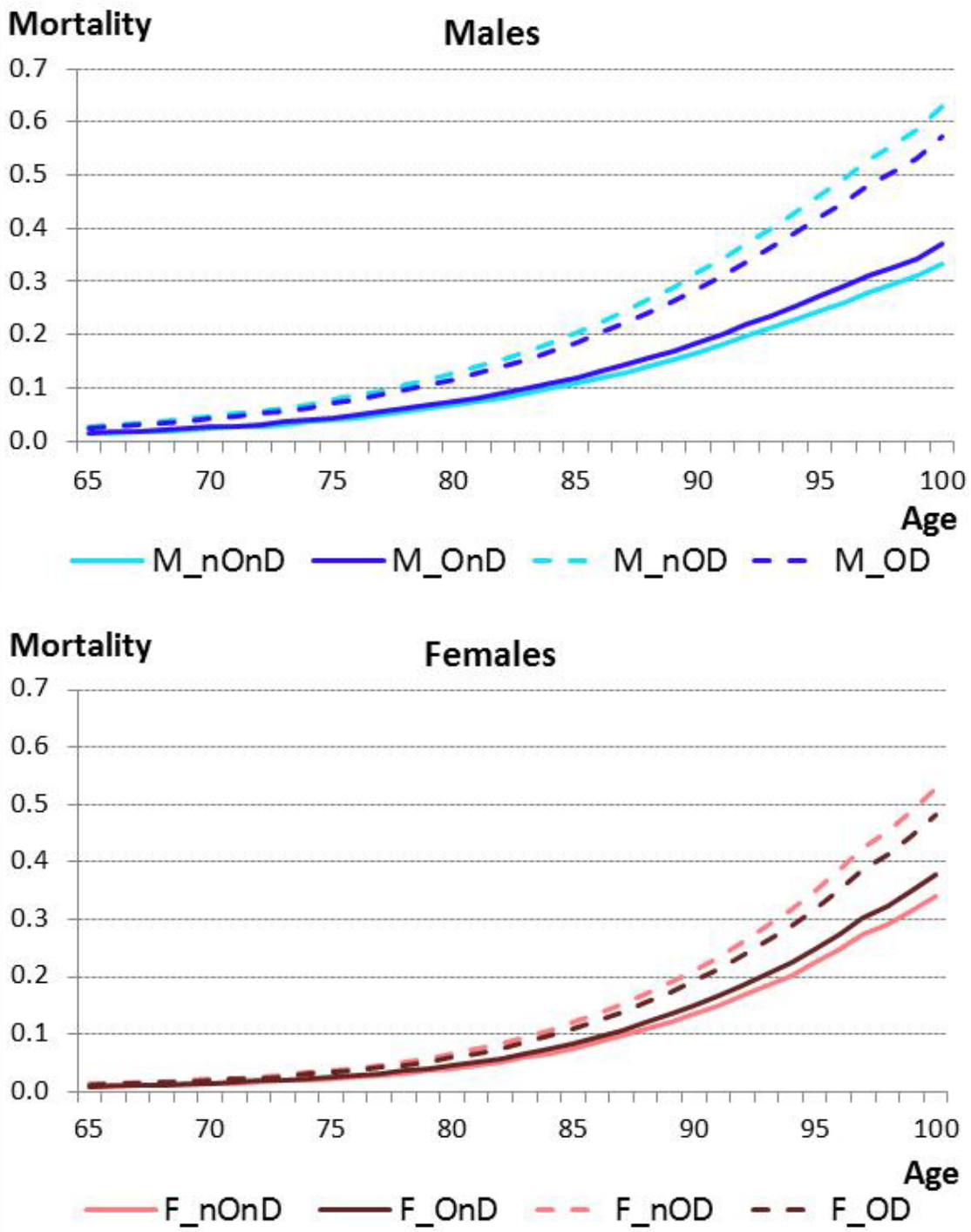

Notes: M_nOnD: males, not-obese, non-disabled $M$ nOD: males, not obese, disabled

F_nOnD: females, not-obese, non-disabled

F_nOD: females, not obese, disabled
M_OnD: males, obese, non-disabled M OD: males, obese, disabled F_OnD: females, obese, non-disabled F_OD: females, obese, disabled. 
Figure 9: Trends in disability prevalence of the elderly (65+), obesity scenarios, the Netherlands

\section{Index prevalence $\mathbf{2 0 0 8}=\mathbf{1 0 0}$}

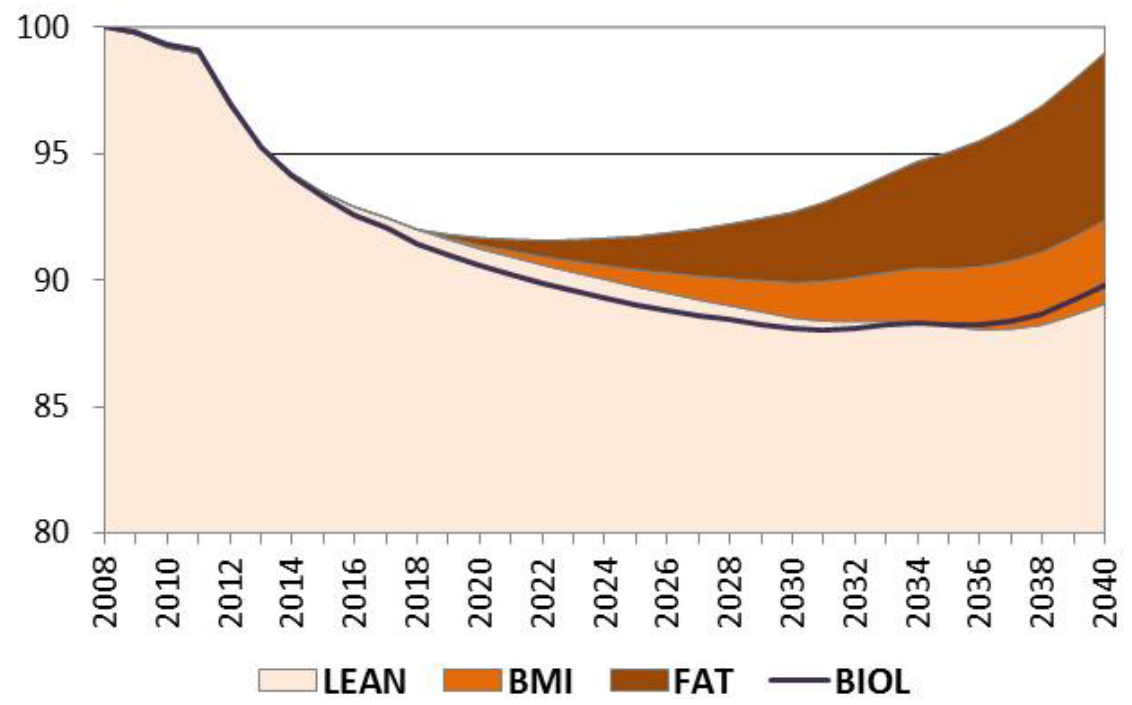

\section{Discussion}

As a result of population ageing the numbers of elderly in the European Union will increase substantially in the coming decades. Since long-term care consumption by the elderly is well above average, the need for care may also increase significantly. The need for care depends on disabilities in the basic activities of daily living (ADL): getting out of bed, dressing, washing, going independently to the toilet and eating without help. To address health care policy questions in ageing societies therefore, it is important to know how many elderly people will face ADL-disability. Future numbers of disabled elderly can be calculated based on disability prevalence data using the Sullivan method, or based on disability incidence data using multistate models. The strength of a multistate model is that the relationship between changes in mortality and disability is taken into account and that the effects of risk factors on both mortality and disability can be estimated. This may improve the transparency of the projections. The weaknesses of the method are the high data requirements and the need for several simplifying assumptions. Although in principle, incidence rates can be estimated from panel studies such as SHARE, the samples in successive survey rounds are generally 
too small to directly estimate disability incidence rates. Therefore this paper describes an estimation procedure for calculating disability incidence rates from disability prevalence rates and mortality rates.

We illustrated the procedure to estimate disability incidence from disability prevalence using the irreversible illness-death model to compile two sets of scenarios of future disability among the elderly in the Netherlands. The first set is based on assumptions about the relationship between changes in mortality and changes in the incidence of disability. The second set includes the risk factor obesity and covers additional assumptions about changes in the prevalence of obesity. Although we have to be careful in our conclusions given the various simplifying assumptions we had to make, the results show that in the constant disability incidence scenario disability prevalence will increase, even though the mortality rates of disabled persons exceed those of non-disabled people. The biological scenario with declining incidence on the other hand significantly lowers the estimates of ADL-disability prevalence. Adding risk factors to the projections may improve the understanding of the underlying processes. While assuming current obesity levels to remain constant in the future will result in a slightly smaller decline of disability prevalence than the biological scenario, the results of the scenario assuming a strong reduction of age-specific obesity are highly similar to the biological scenario. This could mean that the prevalence of obesity should be seriously reduced to reach a strong reduction of disability incidence or that a strong reduction of disability incidence, as assumed in the biological scenario, is too optimistic given current patterns of obesity.

Even though our main interest is to estimate disability prevalence based on different assumptions of disability incidence, it is interesting to note that in all scenarios the absolute number of persons with at least one ADL-limitation will continue to grow until 2040. Even according to the most optimistic scenarios with estimated reductions of disability prevalence of almost 20 per cent, the predicted number of persons with ADL-limitations in 2040 is still expected to be about 75 to 80 per cent larger than in 2008. This shows the overriding influence of demographic change, or the ageing of the baby boom generations, on future numbers of disabled elderly. This is partly because of demographic inertia. It takes many years to replace a population. A higher prevalence of obesity increases the prevalence of disability, but in absolute numbers the increase is relatively limited compared with the demographic growth of the elderly population. According to the scenario assuming a doubling of obesity at age 55, the predicted number of persons with ADL-limitations in 2040 is expected to increase slightly more than 90 per cent. Even though all individuals of the baby boom generations that survive until 2040 will contribute to the elderly population, only a (small) part of them will be at increased risk of disability. 
We have to keep in mind, however, that the data used are weak. Prevalence of basic ADL-disability is highest among the oldest old population, but data on the prevalence of basic ADL-disability in these populations are rare or absent. Therefore, we are more confident of the modelled trends in prevalence of ADL-disability, than of the estimate of basic ADL-disability for 2008 and the resulting estimates of absolute numbers of future disabled elderly. Only significant changes in the age distributions of the population or in obesity prevalence make these trends less certain, while even modest changes in the point estimate of ADL-disability at the start of the projection can result in significant differences in the estimates of future numbers of disabled elderly. Finally, we assumed equal mortality trends for disabled and non-disabled persons, as well as for obese and non-obese people. This may, and probably will not be true. Notwithstanding these remarks we may conclude that the improved transparency of the projections, the generic nature of the model and the applicability to all countries with available disability prevalence data, make this method a useful instrument to study future trends in disability prevalence based on different assumptions of disability incidence.

\section{Acknowledgements}

The research presented in this paper was conducted in the context of the ANCIEN project (Assessing Needs of Care in European Nations), which focuses on the future of long-term care for the elderly in Europe (http://www.ancien-longtermcare.eu/). This project was funded by the European Commission under the 7th Framework Programme (Grant agreement no. 223483; FP7 Health-2007-3.2.2). The authors gratefully acknowledge the valuable comments of the editors and two anonymous reviewers. 


\section{References}

Aalen, O., Borgan, O., and Gjessing, H. (2008). Survival and Event History Analysis: A Process Point of View. New York: Springer. doi:10.1007/978-0-387-68560-1.

Ageing Working Group (2009). 2009 Ageing Report: Economic and budgetary projections for the EU-27 Member States (2008-2060). Luxembourg: European Communities. (Joint report prepared by the European Commission (DG ECFIN) and the Economic Policy Committee (AWG); European Economy 2/2009).

Barendregt, J.J., Van Oortmarssen, G.J., Vos, T., and Murray, C.J.L. (2003). A generic model for the assessment of disease epidemiology: The computational basis of DisMod II. Population Health Metrics 1(1): 1-8. doi:10.1186/1478-7954-1-4.

Bonneux, L. (2011). Mortality avoidable by health care and public health and policy interventions. In: Rogers, R.G. and Crimms, E.M. (eds.). International Handbook of Adult Mortality. New York: Springer: 583-608. doi:10.1007/97890-481-9996-9_28.

Bonneux, L., Barendregt, J.J., Meeter, K., Bonsel, G.J., and Van der Maas, P.J. (1994). Estimating clinical morbidity due to ischemic heart disease and congestive heart failure: the future rise of heart failure. American Journal of Public Health 84(1): 20-28. doi:10.2105/AJPH.84.1.20.

Bonneux, L., Van der Gaag, N., Bijwaard, G., Mot, E., and Willemé, P. (2012). Demographic Epidemiologic Projections of Long-term Care Needs in selected European countries: Germany, Spain, the Netherlands and Poland. Brussels: European Network of Economic Policy Research Institutes (ENEPRI Policy Brief No. 8).

Cai, L. and Lubitz, J. (2007). Was there compression of disability for older Americans from 1992 to 2003? Demography 44(3): 479-495. doi:10.1353/dem.2007.0022.

Cetin, D.C. and Nasr, G. (2014). Obesity in the elderly: More complicated than you think. Cleveland Clinic Journal of Medicine 81(1): 51-61. doi:10.3949/ccjm.81 a.12165.

Christensen, K., Doblhammer, G., Rau, R., and Vaupel, J.W. (2009). Ageing populations: the challenges ahead. The Lancet 374(9696): 1196-1208. doi:10.10 16/S0140-6736(09)61460-4. 
Van der Gaag et al.: A multistate model to project elderly disability in case of limited data

Comas-Herrera, A., Wittenberg, R., Costa-Font, J., Gori, C., Dimaio, A., Patxot, C., Pickard, L., Pozzi, A., and Rothgang, H. (2006). Future long-term care expenditure in Germany, Spain, Italy and the United Kingdom. Ageing \& Society 26(2): 285-302. doi:10.1017/S0144686X05004289.

De Beer, J., Van der Gaag, N., Van der Erf, R., Bauer, R., Fassmann, H., Kupiszewska, D., Kupiszewski, M., Rees, P., Boden, P., Dennett, A., Jasińska, M., Stillwell, J., Wohland, P., De Jong, A., Ter Veer, M., Roto, J., Van Well, L., Heins, F., Bonifazi, C., and Gesano, G. (2010). Demographic and migratory flows affecting European regions and cities. Final Report DEMIFER. Luxembourg: ESPON (The ESPON 2013 Programme, Applied Research Project 2013/1/3).

Diamond, I.M. and McDonald, J.W. (1992). Analysis of current status data. In: Trussel, J., Hankinson, R., and Tilton, J. (eds.). Demographic Applications of Event History Analysis. Oxford: Clarendon Press: 231-252.

Eurostat (2008). Population projections 2008-2060 - from 2015, deaths projected to outnumber births in the EU27. Luxembourg: European Commission (News release No. 119/2008, 26/8/2008).

Eurostat (2011). Population projections [electronic resource]. Luxembourg: European Commission. [http://epp.eurostat.ec.europa.eu/statistics_explained/index.php/ Population_projections].

Eurostat (2014). EUROPOP2013 - Population projections at national level [electronic resource]. Luxembourg: European Commission. [http://epp.eurostat.ec.europa. eu/cache/ITY_SDDS/en/proj_13n_esms.htm].

Felson, D.T., Anderson, J.J., Naimark, A., Walker, A.M., and Meenan, R.F. (1988). Obesity and knee osteoarthritis. The Framingham Study. Annals of Internal Medicine 109(1):18-24. doi:10.7326/0003-4819-109-1-18.

Fries, J.F. (1980). Aging, natural death, and the compression of morbidity. New England Journal of Medicine 303(3): 130-135. doi:10.1056/NEJM19800717303 0304.

Gray, A. (2005). Population aging and health care expenditure. Ageing Horizons 2: 1520.

Han, T.S., Tajar, A., and Lean, M.E.J. (2011). Obesity and weight management in the elderly. British Medical Bulletin 97: 169-196. doi:10.1093/bmb/ldr002. 
Horani, M.H. and Mooradian, A.D. (2002). Management of obesity in the elderly: special considerations. Treatments in Endocrinology 1(6): 387-398. doi:10.216 5/00024677-200201060-00004.

Hu, F.B., Willett, W.C., Stampfer, M.J., Spiegelman, D., and Colditz, G.A. (2005). Calculating deaths attributable to obesity. American Journal of Public Health 95(6): 932. doi:10.2105/AJPH.2005.062836.

Huisman, C., De Beer, J., Van der Erf, R., Van der Gaag, N., and Kupiszewska, D. (2013). Demographic scenarios 2010-2030. (NEUJOBS Working Paper D10.1, Revised version, March 2013).

Impicciatore, R. and Billari, F. (2011). MAPLES: A general method for the estimation of age profiles from standard demographic surveys (with an application to fertility). Demographic Research 24(29): 719-748. doi:10.4054/DemRes.2011. 24.29.

Jagger, C., Cox, B., and Le Roy, S. (2007). Health expectancy calculation by the Sullivan method: a practical guide. Report European Health Expectancy Monitoring Unit (EHEMU Technical report 2006_3).

Jung, J. (2006). Estimating Markov Transition Probabilities between Health States in the HRS Dataset. Bloomington: Indiana University (Working paper).

Katz, S., Ford, A.B., Moskowitz, R.W., Jackson, B.A., and Jaffe, M.W. (1963). Studies of Illness in the Aged. the Index of BADL: a Standardized Measure of Biological and Psychosocial Function. Journal of the American Medical Association 185(12): 914-919. doi:10.1001/jama.1963.03060120024016.

KC, S. and Lutz, W. (2014). Demographic scenarios by age, sex and education corresponding to the SSP narratives. Population and Environment 35(3):243260. doi:10.1007/s11111-014-0205-4.

Keiding, N. (1991). Age-specific incidence and prevalence: A statistical perspective (with discussion). Journal of the Royal Statistical Society: Series A (Statistics in Society) 154(3): 371-412. doi:10.2307/2983150.

Khoman, E., Mitchell, J., and Weale, M. (2008). Incidence-based estimates of life expectancy of the healthy for the UK: coherence between transition probabilities and aggregate life-tables. Journal of the Royal Statistical Society. Series A (Statistics in Society) 171(1): 203-222. doi:10.1111/j.1467-985X.2007.0049 7.x. 
Van der Gaag et al.: A multistate model to project elderly disability in case of limited data

Losina E., Walensky, R.P., Reichmann, W.M., Holt, H.L., Gerlovin, H., Solomon, D.H., Jordan, J.M., Hunter, D.J., Suter, L.G., Weinstein, A.M., Paltiel, A.D., and Katz, J.N. (2011). Impact of Obesity and Knee Osteoarthritis on Morbidity and Mortality in Older Americans. Annals of Internal Medicine 154(4):217-226. doi:10.7326/0003-4819-154-4-201102150-00001.

Majer, I.M., Nusselder, W.J., Mackenbach, J.P., and Kunst, A.E. (2011). Life expectancy and life expectancy with disability of normal weight, overweight, and obese smokers and nonsmokers in Europe. Obesity 19(7): 1451-1459. doi:10.1038/oby.2011.46.

Manton, K.G., Gu, X., and Lowrimore, G.R. (2008). Cohort Changes in Active Life Expectancy in the U.S. Elderly Population: Experience From the 1982-2004 National Long-Term Care Survey. The Journals of Gerontology Series B: Psychological Sciences and Social Sciences 63(5): S269-S281. doi:10.1093/gero nb/63.5.S269.

Meerding, W.J., Bonneux, L., Polder, J.J., Koopmanschap, M.A., and Van der Maas, P.J. (1998). Demographic and epidemiological determinants of healthcare costs in Netherlands: cost of illness study. British Medical Journal 317(7151): 111115. doi:10.1136/bmj.317.7151.111.

Meerding, W.J., Polder, J., Bonneux, L., Koopmanschap, M., and Van der Maas, P. (1998). Health-care costs of ageing. The Lancet 351(9096): 140-141. doi:10.101 6/S0140-6736(05)78119-8.

Meira-Machado, L. and Roca-Pardinas, J. (2011). p3state.msm: Analyzing Survival Data from an Illness-Death Model. Journal of Statistical Software 38(3): 1-18.

Mitnitski, A.B., Graham, J.E., Mogilner, A.J., and Rockwood, K. (2002). Frailty, fitness and late-life mortality in relation to chronological and biological age. BioMed Central Geriatrics 2(1): 1. doi:10.1186/1471-2318-2-1.

Mot, E., Aouragh, A., De Groot, M., and Mannaerts, H. (2010). The Long-Term Care System For The Elderly In The Netherlands. (ENEPRI Research Report No. 90).

Oeppen, J. and Vaupel, J.W. (2002). Demography. Broken limits to life expectancy. Science 296(5570): 1029-1031. doi:10.1126/science.1069675.

Olshansky, S.J., Rudberg, M.A., Carnes, B.A., Cassel, B.A., and Brady, J.A. (1991). Trading off longer life for worsening health: the expansion of morbidity hypothesis. Journal of Ageing and Health 3(2): 194-216. doi:10.1177/08982643 9100300205. 
Oreopoulos, A., Kalantar-Zadeh, K., Sharma, A.M., and Fonarow, G.C. (2009). The obesity paradox in the elderly: potential mechanisms and clinical implications. Clin Geratr Med 25(4): 643-659. doi:10.1016/j.cger.2009.07.005.

Pavolini, E. and Ranci, C. (2008). Restructuring the welfare state: reforms in long-term care in Western European countries. Journal of European Social Policy 18(3): 246-259. doi:10.1177/0958928708091058.

Peeters, A., Bonneux, L., Barendregt, J.J., and Mackenbach, J.P. (2003). Improvements in treatment of coronary heart disease and cessation of stroke mortality rate decline. Stroke 34(7): 1610-1614. doi:10.1161/01.STR.0000078661.72578.0A.

Podgor, M.J. and Leske, M.C. (1986). Estimating incidence from age-specific prevalence for irreversible diseases with differential mortality. Statistics in Medicine 5(6): 573-578. doi:10.1002/sim.4780050604.

Pollard J.H., Golini, A., and Milella, G. (1990). On the use of health surveys for estimating transition rates for morbidity processes. Paper presented at the International Conference "Health, Morbidity and Mortality by Causes of Death", Vilnius, Lithuania, December 3-7 1990.

Przywara, B. (2010). Projecting future health care expenditure at European level: drivers, methodology and main results. Brussels: European Union (Economic Papers 417).

Rees, P., Wohland, P., Zuo, C., Norman, P., Jagger, C., Boden, P., and Jasinska, M. (2013). The Implications of Ageing and Migration for the Future Population, Health, Labour Force and Households of Northern England. Applied Spatial Analysis and Policy 6(2): 93-122. doi:10.1007/s12061-013-9086-7.

Reuser, M., Bonneux, L., and Willekens, F. (2008). The burden of mortality of obesity at middle and old age is small. A life table analysis of the US Health and Retirement Survey. European Journal of Epidemiology 23(9): 601-607. doi:10.1007/s10654-008-9269-8.

Reuser, M., Bonneux, L.G., and Willekens, F.J. (2009). Smoking kills, obesity disables: a multistate approach of the US Health and Retirement Survey. Obesity 17(4): 783-789. doi:10.1038/oby.2008.640.

Rodrigues, R., Huber, M., and Lamura, G. (eds.) (2012). Facts and Figures on Healthy ageing and long-term care. Vienna: European Centre for Social Welfare Policy and Research. 
Van der Gaag et al.: A multistate model to project elderly disability in case of limited data

Rogers, A., Rogers, G., and Branch, L.G. (1989). A Multistate Analysis of Active Life Expectancy. Public Health Reports 104(3): 222-226.

Roubenoff, R. (2004). Sarcopenic obesity: the confluence of two epidemics. Obesity Research 12(6): 887-888. doi:10.1038/oby.2004.107.

Scherbov, S., Mamolo, M., and Lutz, W. (2008). Probabilistic Population Projections for the 27 EU Member States Based on Eurostat Assumptions. Vienna: Vienna Institute of Demography (European Demographic Research Paper No. 2).

Singer, B. and Spilerman, S. (1976). The representation of social processes by Markow models. American Journal of Sociology 82(1): 1-54.

Sullivan, D.F. (1971). A single index of mortality and morbidity. HSMHA Health Reports 86(4): 347-354. doi:10.2307/4594169.

Touraine, C., Gerds, T.A., and Joly, P. (2013). The SmoothHazard package for R: Fitting regression models to interval-censored observations of illness-death models. Copenhagen: University of Copenhagen, Department of Biostatistics (Research Report 13/12).

United Nations (2014). World Population Prospects: The 2012 Revision. New York: United Nations Department of Economic and Social Affairs, Population Division.

Van de Kassteele, J., Hoogenveen, R.T., Engelfriet, P.M., Van Baal, P.H.M., and Boshuizen, H.C. (2012). Estimating net transition probabilities from crosssectional data with application to risk factors in chronic disease modeling. Statistics in Medicine 31(6): 533-543. doi:10.1002/sim.4423.

Van Imhoff, E. and Keilman, N. (1991). LIPRO 2.0: an application of a dynamic demographic projection model to household structure in the Netherlands. Amsterdam/Lisse: Swets \& Zeitlinger (NIDI/CBGS Publications nr. 23).

Vaupel, J.W. (2010). Biodemography of human ageing. Nature 464(7288): 536-542. doi:10.1038/nature08984.

Walter, S., Kunst, A., Mackenbach, J., Hofman, A., and Tiemeier, H. (2009). Mortality and disability: the effect of overweight and obesity. International Journal of Obesity 33: 1410-1418. doi:10.1038/ijo.2009.176.

Wannamethee, S.G., Shaper, A.G., Whincup, P.H., and Walker, M. (2000). Characteristics of older men who lose weight intentionally or unintentionally. American Journal of Epidemiology 151(7): 667-675. doi:10.1093/oxfordjournal s.aje.a010261. 